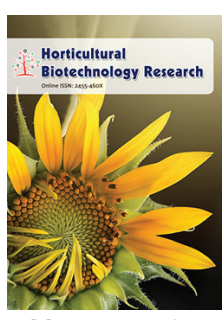

ISSN: $2455-460 X$
Received: September 14, 2021 Revised: December 18, 2021

Accepted: December 23, 2021

Published: December 30, 2021

*Corresponding Author: Taufiqur Rahman Sarkar, Email: nayonbot@yahoo.com

\section{Propagation of Coccinia cordifolia (L.) Cogn. from shoot tip and nodal segment through micropropagation techniques}

\author{
Md. Taufiqur Rahman Sarkar ${ }^{1 *}$, Md. Mizanur Rahman², \\ Mohammad Firoz Alam²
}

'Department of Botany, Joypurhat Government College, Joypurhat, Bangladesh, ${ }^{2}$ Department of Botany, University of Rajshahi, Bangladesh

\begin{abstract}
The present work was undertaken to develop a reproducible protocol for the micropropagation of an important medicinal plant of the Cucurbitaceae family, Coccinia cordifolia (L.) Cogn., by using shoot tips and nodal segments to overcome the impediment in seed settings and seed germination of conventional reproduction. To develop an efficient protocol, $0.1 \%$ $\mathrm{HgCl}_{2}$ treatment for 6 minutes was found effective for surface sterilization of field-grown explants to eliminate microbes and fungus and to get healthy tissues. Throughout the study, different concentrations of auxin, cytokine, and gibberellin were used either alone or in combination as supplemented in MS medium to find suitable conditions and suitable explant (nodal segment). BAP was the best cytokine source as $2.0 \mathrm{mg} / \mathrm{L} \mathrm{BAP}$ produced significantly $(\mathrm{P}<0.05)$ highest $4.0 \pm 0.20$ and $4.8 \pm 0.09$ shoots per culture and gained $5.8 \pm 0.11 \mathrm{~cm}$ and $6.7 \pm 0.32 \mathrm{~cm}$ length with regeneration rate of 90 and 100 percent in shoot tips and node, respectively. The highest percentage $(90 \%)$ of regeneration for axillary shoot proliferation was also obtained in node explants at MS medium containing $2.0 \mathrm{mg} / \mathrm{L} \mathrm{BAP}+0.1 \mathrm{mg} / \mathrm{L} \mathrm{NAA}$. The highest number of shoots regenerated per culture was $3.0 \pm 0.41$, with a length of $6.0 \pm 0.16 \mathrm{~cm}$. GA 3 was also found effective in producing longer shoots with the combination of BAP, but the average shoot number and response rate was reduced drastically. Although full-strength MS medium was found to be ideal for shoot regeneration and used in shoots proliferated experiments, half and full-strength of MS medium with auxins supplements of $0.5,1.0$, and $2.0 \mathrm{mg} / \mathrm{L}$ either of IBA, NAA, and IAA) were used for roots growth and half strength nutrients supplemented with $0.5 \mathrm{mg} / \mathrm{L}$ IBA was found most compelling. The number of roots regenerated per shoot was $3.1 \pm 0.30$, and the average root length was $1.8 \pm 0.30 \mathrm{~cm}$ which are significantly $(P<0.05)$ highest in $0.5 \mathrm{mg} / \mathrm{L}$ IBA. Rooted plantlets were finally transplanted into small plastic pots containing sun sterilized sand, soil and humus ( $1: 2$ : 1) to adapt the plantlet in ex vitro environment, and acclimatized plantlets showed $95 \%$ survival rate in outdoor condition which proved the effectiveness of using biotechnology to improve plant's growth rate and mass production.
\end{abstract}

KEYWORDS: Cocconia cordifolia, micropropagation, axillary shoots, plant growth regulators, shoot regeneration

\section{INTRODUCTION}

Coccinia cordifolia (L.) Cogn. (Synonym: Coccinia indica, Coccinia grandis), a wildly grown medicinal plant, locally known as 'Telakucha' in Bangladesh, belonging to the family Cucurbitaceae of Magnoliopsida class. The plant is a dioecious climbing perennial herbs with thick, tuberous rootstock, a soft stem that consisted alternatively arranged distinctly shaped (heart or pentagon) fleshy leaves, funnel-shaped pure white coloured flower with five sepals and five petals flower and fruits contain rectangular-shaped seeds, are ovoid to ellipsoid or cylindrical and $2.5-6.0 \mathrm{~cm}$ in length and $1.5-3.5 \mathrm{~cm}$ in diameter in size (Yadav et al., 2010; Hussain et al., 2011; Pekamwar et al.,
2013). The plant is indigenous to the Indian sub-continent and can also be found in East and Southeast Asia, tropical Africa, Australia, Fiji. The plant grows abundantly on the roadside, fallow places, adjoining open areas except for house yards in Bangladesh (Roy \& Khan, 2020).

Traditionally, Coccinia cordifolia (L.) Cogn. has been using not only for culinary purposes as a pickle, in salads marinade, on crudité platters, and in salsa, or Indian curries but also as a curative agent. It has been applied in traditional medicine since ancient times all around the world. In Bangladesh, local people use roots to treat osteoarthritis and joint pain, and leaves paste to treat scabies by applying to the skin (Zakaria

Copyright: $\odot$ The authors. This article is open access and licensed under the terms of the Creative Commons Attribution License (http://creativecommons.org/licenses/by/4.o/) which permits unrestricted, use, distribution and reproduction in any medium, or format for any purpose, even commercially provided the work is properly cited. Attribution - You must give appropriate credit, provide a link to the license, and indicate if changes were made. 
et al., 2011). Moreover, the plant has been used widely in ayurvedic diabetes mellitus 2 (Patel \& Ishnava, 2015). This ethnobotanical knowledge was further investigated in alloxan diabetic albino rats, streptozotocin included diabetic rats, and clinically trailed with extracted aerial parts within type 2 diabetes patients and found effective as antidiabetic (Shakya, 2008; Kuriyan et al., 2008). Jamwal and Kumar (2018) isolated Quercetin from the aerial parts and concluded it as an active component for the antidiabetic activity C. cordifolia. Plant parts: roots, leaves, fruits, stems have shown strong scavenging potentiality of free radical because of the presence of a high concentration of glycoside, flavonoid, phenol (Pekamwar et al., 2013; Nachimuthu et al., 2018). Moreover, aerial parts contain heptacosane, cephalandrol, $\beta$-sitosterol, alkaloids, cephalandrins a and $\mathrm{b} ; \beta$ - amyrin acetate, lupeol, cucurbitacin $\mathrm{b}$, taraxerone, taraxerol, $\beta$-carotene, lycopene, cryptoxanthin, xyloglucan, carotenoids, $\beta$-sitosterol, stigma-7-en-3-one present in fruits and roots contain resin, alkaloids, starch, fatty acids, carbonic acid, triterpenoid, saponin, coccinoside, flavonoid, glycoside, lupeol, $\beta$-amyrin, $\beta$-sitosterol, taraxerol (Pekamwar et al., 2013). All these phytochemicals are responsible for the pharmaceutical importance of the plants as plant extract act against worms by paralyzing the worms (Tamilselvan et al., 2011), also effective in reducing fever by influencing the prostaglandin biosynthesis (Agarwal et al., 2011). Leaves extract with solvents like aqueous, chloroform, acetone, ethanol, methanol, and hexane showed significant antibacterial and antifungal activity against Shigella flexneri NICED, Bacillus subtilis Escherichia coli, Salmonella choleraesuis, Shigella dysenteries, and Shigella flexneri, Staphylococcus aurous, Sarcina lutea, Pseudomonas aeruginosa, Aspergillus niger, Candida albicans (Bhattacharya et al., 2010; Sivaraj et al., 2011). Anticancer activity of leaves extract was also reported (Bhattacharya et al., 2011); leaves extract also act against parasite Plasmodium falciparum thus showed excellent antiplasmodial activity (Ravikumar et al., 2012); in reducing ulcer index, free acidity and gastric (Girish et al., 2011). The fruit possesses mast cell stabilizing, antianaphylactic, and antihistaminic potential (Taur \& Patil, 2011). Stem showed activity as an anti-inflammatory (Deshpande, 2011), antispasmodic, and have potency against asthma, bronchitis, urinary tract infection, skin diseases, and root has the potentiality against hypoglycemia, diabetes, skin diseases, joint pain, urinary tract infection (Pekamwar et al., 2013).

Hence, the global market has an increasing demand for medicinal nutritional supplements such as "sugar and fat balance" made from the plant for the natural relief of diabetes, chronic sinusitis, psoriasis, pruritus, wounds, pityriasis, gonorrhea, urinary tract infections and respiratory diseases (Kashem \& Rahman, 2018). However, C. cordifolia is a seed germinating plants and due to presence of a thin nuclear membrane which makes seed impervious to water and gas, and makes them inactive for many days and lower the germination rate thus causing a decline in the number of population (Devendra et al., 2008). Therefore, in vitro shoot regeneration technology has been adopted to overcome the impediment of seed germination as an alternative method of propagation to produce the medicinally important plant in large scale with genetic uniformity to utilize their active chemical components in the pharmaceutical industry (Alam et al., 2010; Sharmin et al., 2013). Shoot apex, nodal segment, leaf, internode has been utilized to produce the plantlets by direct and indirect organogenesis method in aseptic condition for the plants C. cordifolia (Sarker et al., 2009; Sundari et al., 2011; Kashem and Rahman, 2018; Borah et al., 2019). To determine the reproducibility of the former techniques, the present study was undertaken by overcoming the problems associated with conventional reproduction through developing a suitable reproducible micropropagation protocol from shoot tips and nodes.

\section{MATERIALS AND METHODS}

\section{Collection of Plant Samples}

Fresh and healthy immature explants including shoot tips and nodes of Coccinia cordifolia (L.) Cogn. were collected from the University of Rajshahi, Bangladesh. The location is at $24^{\circ} 22^{\prime}$ 20.74"N latitude and 88 $38^{\prime} 12.65^{\prime \prime}$ "E longitude with an elevation of 23 meters from the sea level.

\section{Culture Medium}

Murashige and Skoog medium (MS medium) (Murashige and Skoog, 1962) containing 3\% (w/v) sucrose (commercial sugar) and $0.75 \%(\mathrm{w} / \mathrm{v})$ agar (for semisolid texture) and different growth hormones (BAP, Kin, NAA, IBA, IAA) were used as the basal growth medium for culture.

\section{Explants Sterilization}

Explants with $3-4 \mathrm{~cm}$ in length, thoroughly washed several times under running tap water to reduce the dust and the contaminants, then put a few drops of savlon and a few drops of tween 20 (polyoxyethylene sorbitan monolaurate) in a conical flask with distilled water and washed 2-3 times with sterile distilled water. The materials were then transferred to a sterile $250 \mathrm{ml}$ conical flask. Surface sterilization was then carried out in a running laminar airflow cabinet by adding $0.1 \% \mathrm{HgCl}_{2}$ solution with gentle agitating for 3-10 min followed by sterile distilled water was for 3-5 times.

\section{Shoot Induction and Proliferation}

Shoot-tip and nodal explants were used for axillary shoot proliferation and cultured on different strengths of MS medium (Murashige \& Skoog, 1962), MS (full strength), $\mathrm{MMS}_{1}(1 / 2$ strength of major salts but full strength of minor salts) and $\mathrm{MMS}_{2}$ (1/2 strength of major salts and minor salts) by using growth regulators of $1.0 \mathrm{mg} / \mathrm{L} \mathrm{BAP}, 1.5 \mathrm{mg} / \mathrm{L} \mathrm{BAP}$, $2.0 \mathrm{mg} / \mathrm{L}$ BAP, $1.0 \mathrm{mg} / \mathrm{L} \mathrm{BAP}+0.1 \mathrm{mg} / \mathrm{L} \mathrm{NAA}, 1.5 \mathrm{mg} / \mathrm{L} \mathrm{BAP}+$ $0.1 \mathrm{mg} / \mathrm{L} \mathrm{NAA}$ and $2.0 \mathrm{mg} / \mathrm{L} \mathrm{BAP}+0.1 \mathrm{mg} / \mathrm{L} \mathrm{NAA}$ in each nutrient medium.

Then, the best responsive nutrient medium was applied with various concentrations of supplemented either of BAP at concentrations $1.0,2.0,2.5$, and $3.0 \mathrm{mg} / \mathrm{L}$ or with a combination of $0.1,0.2$, and $0.5 \mathrm{mg} / \mathrm{L}$ either of NAA, IBA, IAA, and $\mathrm{GA}_{3}$ for selecting optimum hormonal concentration and better explants type. 


\section{In vitro root induction}

For root formation, in vitro grown shoots were cut off and cultured in both full and half strength MS media supplemented with $0.5,1.0$, and $2.0 \mathrm{mg} / \mathrm{L}$ of either IBA, NAA, IAA to unearth the effects of this auxin on roots growth and development of in vitro regenerated shoots.

\section{Culture Incubation}

All cultures were maintained in a growth chamber for 16-hours photoperiod with 2000-3000 lux light intensity provided by warm 40 watts white fluorescent tubular lamp at controlled temperature of $25 \pm 2^{\circ} \mathrm{C}$. However, humidity was not controlled for any of the experiments.

\section{Acclimatization}

To transplant the in vitro grown plantlets into soil, agar gel was removed from the root system by continuous washing of running tap water. Then small plastic pots containing sun sterilized sand, soil, and humus (1:2:1) were used to transfer the plantlets. The potted plants were hardened in a greenhouse. The transplants were then gradually acclimatized to outdoor conditions. The potted plants were watered adequately and covered with a perforated polythene bag and kept in a room for 10-15 days.

\section{Statistical Analysis}

All the experiments were repeated 3 times, with 7 repetitions for each and every treatment. Surface disinfection data was recorded once after 5 days and then after 10 days. After 5 weeks of cultivation, the data of different parameters from different bud proliferation treatments were recorded, and the data of the rooting experiment was recorded after 3-6 weeks of cultivation. The average value with standard errors were calculated and mean data were compared at $5 \%$ significance level by one-way ANOVA followed by Duncan's Multiple Range Test (DMRT) using SPSS Statistics 23 software.

\section{RESULTS}

\section{Surface Sterilization of Explants}

$\mathrm{HgCl}_{2}$ solution is usually used as one of the potential surfacesterilizing agents. However, the non-judicious application of $\mathrm{HgCl}_{2}$ solution for a long duration may thwart proliferation and kill the excised tissues in many cases. Standardization of the surface sterilization protocol is done by trial and error. The shoot tips and nodes of C. cordifolia grown in the field were treated with $0.1 \% \mathrm{HgCl}_{2}$ for aseptic cultivation at different durations, i.e. $3,4,5,6,7,8,9$, and 10 minutes.

Contamination occurred when the explants were treated in $0.1 \%$ $\mathrm{HgCl}_{2}$ solution for 3, 4, and 5 minutes. However, $85 \%$ of the stem tips and $90 \%$ of the node explants were contamination free at the 6 minutes treatment of $0.1 \% \mathrm{HgCl}_{2}$. When the explants were processed for a long time (7-10 minutes), partial or complete tissue death was observed, although, no contamination was found.

\section{Effect of Different Strengths of MS Medium}

For this study, shoot-tip and nodal segment explants were collected from field-grown mature plants and cultured on different strengths of MS medium (Murashige \& Skoog, 1962), MS (full strength), $\mathrm{MMS}_{1}(1 / 2$ strength of major salts but full strength of minor salts), and $\mathrm{MMS}_{2}$ (1/2 strength of major salts and minor salts). The growth regulators at $1.0 \mathrm{mg} / \mathrm{L} \mathrm{BAP,}$ $1.5 \mathrm{mg} / \mathrm{L}$ BAP, $2.0 \mathrm{mg} / \mathrm{L}$ BAP, $1.0 \mathrm{mg} / \mathrm{L} \mathrm{BAP}+0.1 \mathrm{mg} / \mathrm{L} \mathrm{NAA}$, $1.5 \mathrm{mg} / \mathrm{L} \mathrm{BAP}+0.1 \mathrm{mg} / \mathrm{L} \mathrm{NAA}$, and $2.0 \mathrm{mg} / \mathrm{L} \mathrm{BAP}+0.1 \mathrm{mg} / \mathrm{L}$ NAA were used as supplements in each nutrient medium (Table 1). The data presented in table 1 showed that the full strength of MS medium produced the best proliferation concerning for the frequency to explants showing proliferation ranged $40-85 \%$ for shoot-tips and $45-95 \%$ for nodal segments. Number of shoots per explant ranges $1.5 \pm 0.35$ to $4.5 \pm 0.46$ for shoot-tips and $1.7 \pm 0.16$ to $5.0 \pm 0.55$ for nodal segments. The length of the longest shoot was also significantly $(\mathrm{P}<0.05)$ higher in that medium irrespective of growth regulator supplements.

The proliferation of shoots was found slower on MMS and $\mathrm{MMS}_{2}$ media than that of on MS medium. The shoots produced on these media were unhealthy in their growth and vigor. Considering the experiment results, the only full strength of MS medium was used as a basal medium in the subsequent study for proliferating shoots or regenerating plantlets of C. cordifolia.

\section{Selection of Suitable Explants and Effective Cytokine}

Axillary shoot proliferation was induced in two types of explants, including shoot-tip and nodal segments on MS medium with $1.0,2.0$, and $3.0 \mathrm{mg} / \mathrm{L}$ of PGRs like BAP, and Kin separately for selecting optimum cytokine concentration and better explants type. The maximum shoot production was $90 \%$ and $100 \%$ for shoot-tip and nodal explants, respectively (Figure lc-d). After 5 weeks of incubation, the data of number of shoots per explant and the average length of shoots per culture from different treatments were recorded, and the results are shown in Table 2.

The concentrations of the cytokines used in the present investigation amazingly influenced the regeneration of axillary shoot from the cultured shoot-tip and nodal explants. At most concentrations, the cytokine BAP is relatively more effective in increasing axillary shoots, while Kin is much less effective. With the increase of cytokine concentrations from 1.0 to $2.0 \mathrm{mg} / \mathrm{L}$, the proliferation percentage and the shoots number per culture gradually increased. Although a further increase in cytokine concentrations from $2.0 \mathrm{mg} / \mathrm{L}$ to $3.0 \mathrm{mg} / \mathrm{L}$ did not lessen any of the parameters, reduced the increase of shoots. The media containing 1.0, 2.0, and $3.0 \mathrm{mg} / \mathrm{L}$ of BAP treatments induced axillary shoots from shoot-tip and nodal explants with response rate of $55 \%$ and $65 \%, 90 \%$ and $100 \%$, and $45 \%$ and $50 \%$, respectively, and the number of shoots per explant ranges $1.9 \pm 0.33-4.0 \pm 20$ for shoot tips and 2.3 $\pm 0.16-$ $4.8 \pm 0.09$ for nodal explants (Table 2 ). So, the most preferred 
Table 1: Different levels of nutrients in MS medium and effect on plant regeneration rate, shoots number and shoots length. Same letters in the same column indicate no significant differences between mean \pm SE of treatments at $5 \%$ significance level

\begin{tabular}{|c|c|c|c|c|c|}
\hline Growth regulators (mg/L) & Different nutrient media & Types of explants & $\begin{array}{l}\text { Response of } \\
\text { explants (\%) }\end{array}$ & $\begin{array}{l}\text { No. of shoots per } \\
\text { culture }(\bar{X} \pm \text { S.E. })\end{array}$ & $\begin{array}{c}\text { Length of the shoot }(\mathrm{cm}) \\
(\bar{X} \pm \text { S.E. })\end{array}$ \\
\hline \multicolumn{6}{|l|}{ BAP } \\
\hline & \multirow[t]{2}{*}{ MS } & ST & 40 & $1.5 \pm 0.35^{\mathrm{e}}$ & $1.8 \pm 0.12^{\mathrm{e}}$ \\
\hline & & NS & 45 & $1.7 \pm 0.16^{\mathrm{e}}$ & $2.0 \pm 0.33^{e}$ \\
\hline \multirow{6}{*}{1.0} & \multirow{2}{*}{$\mathrm{MMS}_{1}$} & ST & 30 & $1.4 \pm 0.50^{\mathrm{e}}$ & $1.7 \pm 0.25^{\mathrm{e}}$ \\
\hline & & NS & 35 & $1.5 \pm 0.34^{\mathrm{e}}$ & $1.9 \pm 0.44^{e}$ \\
\hline & \multirow{2}{*}{$\mathrm{MMS}_{2}$} & ST & 20 & $1.2 \pm 0.24 \mathrm{e}^{f}$ & $1.2 \pm 0.34^{f}$ \\
\hline & & NS & 25 & $1.3 \pm 0.51 \mathrm{e}^{f}$ & $1.5 \pm 0.22 \mathrm{e}^{f}$ \\
\hline & \multirow[t]{2}{*}{ MS } & ST & 65 & $3.5 \pm 0.45 c^{d}$ & $3.9 \pm 0.27^{c}$ \\
\hline & & NS & 75 & $3.9 \pm 0.26 b^{c}$ & $4.0 \pm 0.51^{c}$ \\
\hline \multirow[t]{6}{*}{1.5} & \multirow{2}{*}{$\mathrm{MMS}_{1}$} & ST & 45 & $2.5 \pm 0.39^{d}$ & $3.1 \pm 0.31^{d}$ \\
\hline & & NS & 55 & $2.7 \pm 0.37^{d}$ & $3.5 \pm 0.10^{d}$ \\
\hline & \multirow[t]{2}{*}{$\mathrm{MMS}_{2}$} & ST & 35 & $1.4 \pm 0.27^{\mathrm{e}}$ & $1.7 \pm 0.66^{\mathrm{e}}$ \\
\hline & & NS & 40 & $1.5 \pm 0.46^{\mathrm{e}}$ & $1.8 \pm 0.43^{e}$ \\
\hline & \multirow[t]{2}{*}{ MS } & ST & 85 & $4.5 \pm 0.46^{a}$ & $5.8 \pm 0.57^{\mathrm{a}}$ \\
\hline & & NS & 95 & $5.0 \pm 0.55^{a}$ & $6.0 \pm 0.35^{a}$ \\
\hline \multirow[t]{4}{*}{2.0} & \multirow[t]{2}{*}{$\mathrm{MMS}_{1}$} & ST & 75 & $4.1 \pm 0.38^{b}$ & $4.9 \pm 0.41^{b}$ \\
\hline & & NS & 80 & $4.6 \pm 0.12^{\mathrm{a}}$ & $5.0 \pm 0.31^{b}$ \\
\hline & \multirow[t]{2}{*}{$\mathrm{MMS}_{2}$} & ST & 65 & $2.9 \pm 0.31^{d}$ & $3.4 \pm 0.20^{d}$ \\
\hline & & NS & 75 & $3.4 \pm 0.20 c^{d}$ & $3.7 \pm 0.35 c^{d}$ \\
\hline \multicolumn{6}{|l|}{$\mathrm{BAP}+\mathrm{NAA}$} \\
\hline & \multirow[t]{2}{*}{ MS } & ST & 55 & $3.0 \pm 0.49^{c d}$ & $3.3 \pm 0.49^{d}$ \\
\hline & & NS & 60 & $3.2 \pm 0.16^{\mathrm{cd}}$ & $3.6 \pm 0.33^{\text {cd }}$ \\
\hline \multirow[t]{6}{*}{$1.0+0.1$} & \multirow[t]{2}{*}{$\mathrm{MMS}_{1}$} & ST & 40 & $1.6 \pm 0.59^{\mathrm{e}}$ & $1.8 \pm 0.46^{\mathrm{e}}$ \\
\hline & & NS & 45 & $1.8 \pm 0.16^{\mathrm{e}}$ & $2.1 \pm 0.52^{\mathrm{e}}$ \\
\hline & \multirow[t]{2}{*}{$\mathrm{MMS}_{2}$} & ST & 30 & $1.5 \pm 0.36^{\mathrm{e}}$ & $1.4 \pm 0.49^{\mathrm{ef}}$ \\
\hline & & NS & 35 & $1.7 \pm 0.31^{\mathrm{e}}$ & $1.7 \pm 0.33^{\mathrm{e}}$ \\
\hline & \multirow[t]{2}{*}{ MS } & ST & 75 & $4.2 \pm 0.36^{b}$ & $4.7 \pm 0.39^{b}$ \\
\hline & & NS & 80 & $4.8 \pm 0.55^{b}$ & $4.9 \pm 0.28^{b}$ \\
\hline \multirow[t]{6}{*}{$1.5+0.1$} & \multirow[t]{2}{*}{$\mathrm{MMS}_{1}$} & ST & 55 & $3.6 \pm 0.24^{b c}$ & $3.7 \pm 0.12^{c}$ \\
\hline & & NS & 60 & $3.7 \pm 0.20^{b c}$ & $4.0 \pm 0.47^{c}$ \\
\hline & \multirow[t]{2}{*}{$\mathrm{MMS}_{2}$} & ST & 35 & $1.6 \pm 0.35^{\mathrm{e}}$ & $2.9 \pm 0.25^{d}$ \\
\hline & & NS & 45 & $1.2 \pm 0.22^{\mathrm{ef}}$ & $3.0 \pm 0.11^{d}$ \\
\hline & \multirow[t]{2}{*}{ MS } & ST & 75 & $4.4 \pm 0.35^{\mathrm{a}}$ & $5.0 \pm 0.24^{b}$ \\
\hline & & NS & 85 & $4.9 \pm 0.70^{\mathrm{a}}$ & $5.5 \pm 0.11^{b}$ \\
\hline \multirow[t]{4}{*}{$2.0+0.1$} & \multirow[t]{2}{*}{$\mathrm{MMS}_{1}$} & ST & 65 & $3.7 \pm 0.33^{b c}$ & $4.0 \pm 0.20^{c}$ \\
\hline & & NS & 70 & $3.9 \pm 0.44^{b c}$ & $4.3 \pm 0.35^{c}$ \\
\hline & \multirow[t]{2}{*}{$\mathrm{MMS}_{2}$} & ST & 55 & $3.1 \pm 0.23^{\text {cd }}$ & $3.1 \pm 0.29^{d}$ \\
\hline & & NS & 60 & $3.4 \pm 0.31^{c}$ & $3.4 \pm 0.33^{\text {cd }}$ \\
\hline
\end{tabular}

$\mathrm{ST}=$ Shoot Tip; NS = Nodal Segment; MS = Full strength of major and minor nutrients; $\mathrm{MSS}_{1}=1 / 2$ strength of major nutrients but full strength of minor nutrients; $\mathrm{MMS}_{2}=1 / 2$ strength of major nutrients and minor nutrients

concentration is $2.0 \mathrm{mg} / \mathrm{L}$ of BAP as the other cytokine, Kin, produced a significantly $(\mathrm{P}<0.05)$ lower number of shoots. It was also clearly discerned that the nodal explants were better for maximum axillary shoot proliferation than that of shoot tip explants.

In order to evaluate the combined hormonal effect, in vitro grown shoots were taken as explants and were cultured on MS medium supplemented with 1.0, 2.0, and $2.5 \mathrm{mg} / \mathrm{L}$ of BAP together with three different concentrations $(0.1,0.2$ and $0.5 \mathrm{mg} / \mathrm{L})$ of NAA, IBA, and IAA.

Among all the combinations, lower concentrated $0.1 \mathrm{mg} / \mathrm{L} \mathrm{NAA}$ combined with $2.0 \mathrm{mg} / \mathrm{L}$ BAP showed significantly $(\mathrm{P}<0.05)$ the best proliferation rate in both experimental explants (Table 2).

Axillary shoot proliferation showed a great response of about 85\% and $90 \%$ for shoot tip and node, respectively, on MS medium with $2.0 \mathrm{mg} / \mathrm{L} \mathrm{BAP}+0.1 \mathrm{mg} / \mathrm{L} \mathrm{NAA}$. In this hormonal treatment, shoot tip and node produce $2.8 \pm 0.30$ and $3.0 \pm 0.41$ number of shoots per culture, respectively. The significantly $(\mathrm{P}<0.05)$ highest shoot length for shoot tip explant was $5.6 \pm 0.50 \mathrm{~cm}$ and $6.0 \pm 0.16 \mathrm{~cm}$ was obtained for nodal explant in $2.0 \mathrm{mg} / \mathrm{L} \mathrm{BAP}+0.1 \mathrm{mg} / \mathrm{L} \mathrm{IBA}$ and $2.0 \mathrm{mg} / \mathrm{L} \mathrm{BAP}+0.1 \mathrm{mg} / \mathrm{L}$ NAA, respectively. Furthermore, explants of both types showed a lower response rate and a lower productivity on MS medium with BAP combined with IAA.

\section{Effect of $\mathrm{GA}_{3}$ on Shoot Regeneration}

Gibberellic acid $\left(\mathrm{GA}_{3}\right)$ is essential for lateral shoots induction and to increase the internode's length. 9 types of hormonal combination (1.0, 2.0, and $2.5 \mathrm{mg} / \mathrm{L}$ BAP and 0.1, 0.2, and $0.5 \mathrm{mg} / \mathrm{L} \mathrm{GA}_{3}$ ) were used (Table 3). Nodal segments showed highest response rate of $80 \%$ in $2.0 \mathrm{mg} / \mathrm{L} \mathrm{BAP}+0.1 \mathrm{mg} / \mathrm{L} \mathrm{GA}$. Although the length for both shoot tip and node explants were obtained most in $2.0 \mathrm{mg} / \mathrm{L}$ BAP combined with $0.5 \mathrm{mg} / \mathrm{L} \mathrm{GA}_{3}$ of about $7.3 \pm 0.30 \mathrm{~cm}$ and $7.5 \pm 0.50 \mathrm{~cm}$, respectively, total number 
Table 2: Axillary shoot proliferation from the shoot tips and nodal segments of field-grown plants. Same letters indicate no significant differences between mean \pm SE of treatments $(n=3)$ at $5 \%$ significance level

\begin{tabular}{|c|c|c|c|c|c|}
\hline $\begin{array}{l}\text { Different nutrient } \\
\text { media }\end{array}$ & $\begin{array}{l}\text { Types of } \\
\text { explants } \\
\end{array}$ & $\begin{array}{l}\text { Response of } \\
\text { explants (\%) }\end{array}$ & $\begin{array}{l}\text { No. of total shoots per } \\
\text { culture }(\overline{\mathbf{X}} \pm \text { S.E. })\end{array}$ & $\begin{array}{l}\text { Length of the } \\
\text { shoot }(\mathrm{cm})(\bar{X} \pm \text { S.E. })\end{array}$ & $\begin{array}{l}\text { Basal callus } \\
\text { formation }\end{array}$ \\
\hline \multicolumn{6}{|l|}{ BAP } \\
\hline \multirow{2}{*}{1.0} & ST & 55 & $2.5 \pm 0.20^{\mathrm{cd}}$ & $3.2 \pm 0.25^{g}$ & + \\
\hline & NS & 65 & $2.7 \pm 0.34^{\text {cd }}$ & $3.8 \pm 0.44^{\mathrm{ef}}$ & + \\
\hline \multirow[t]{2}{*}{2.0} & ST & 90 & $4.0 \pm 0.20^{b}$ & $5.8 \pm 0.11^{b}$ & + \\
\hline & NS & 100 & $4.8 \pm 0.09^{a}$ & $6.7 \pm 0.32^{\mathrm{a}}$ & + \\
\hline \multirow[t]{2}{*}{3.0} & ST & 45 & $2.9 \pm 0.20^{c}$ & $3.6 \pm 0.66^{\mathrm{ef}}$ & ++ \\
\hline & NS & 50 & $3.0 \pm 0.25^{c}$ & $4.0 \pm 0.43^{\mathrm{ef}}$ & ++ \\
\hline \multicolumn{6}{|l|}{ Kin } \\
\hline \multirow[t]{2}{*}{1.0} & ST & 50 & $2.0 \pm 0.25^{d}$ & $3.0 \pm 0.41^{g}$ & + \\
\hline & NS & 55 & $2.3 \pm 0.12^{d}$ & $3.3 \pm 0.31^{\mathrm{fg}}$ & + \\
\hline \multirow[t]{2}{*}{2.0} & ST & 80 & $3.8 \pm 0.49^{b}$ & $5.1 \pm 0.55^{\mathrm{cd}}$ & ++ \\
\hline & NS & 85 & $4.0 \pm 0.33^{b}$ & $5.5 \pm 0.20^{c}$ & ++ \\
\hline \multirow[t]{2}{*}{3.0} & ST & 30 & $2.1 \pm 0.36^{d}$ & $3.0 \pm 0.49^{g}$ & + \\
\hline & NS & 35 & $2.6 \pm 0.53^{c d}$ & $3.5 \pm 0.33^{f}$ & + \\
\hline \multicolumn{6}{|l|}{$B A P+N A A$} \\
\hline \multirow[t]{2}{*}{$1.0+0.1$} & ST & 65 & $2.2 \pm 0.25^{d}$ & $4.8 \pm 0.20^{d}$ & + \\
\hline & NS & 70 & $2.4 \pm 0.24^{d}$ & $5.0 \pm 0.34^{d}$ & + \\
\hline \multirow[t]{2}{*}{$1.0+0.2$} & ST & 45 & $1.8 \pm 0.50^{\mathrm{de}}$ & $4.0 \pm 0.45^{\mathrm{ef}}$ & ++ \\
\hline & NS & 50 & $1.9 \pm 0.51^{\mathrm{de}}$ & $4.2 \pm 0.22^{\mathrm{e}}$ & ++ \\
\hline \multirow[t]{2}{*}{$1.0+0.5$} & ST & 30 & $1.3 \pm 0.40^{\mathrm{ef}}$ & $3.0 \pm 0.15^{9}$ & ++ \\
\hline & NS & 35 & $1.5 \pm 0.20^{\mathrm{e}}$ & $3.1 \pm 0.11^{g}$ & ++ \\
\hline \multirow[t]{2}{*}{$2.0+0.1$} & ST & 85 & $2.8 \pm 0.30^{c d}$ & $5.5 \pm 0.50^{c}$ & + \\
\hline & NS & 90 & $3.0 \pm 0.41^{c}$ & $6.0 \pm 0.16^{b}$ & + \\
\hline \multirow[t]{2}{*}{$2.0+0.2$} & ST & 75 & $2.3 \pm 0.25^{d}$ & $4.5 \pm 0.30^{\mathrm{de}}$ & + \\
\hline & NS & 75 & $2.5 \pm 0.25^{d}$ & $4.0 \pm 0.43^{e^{f f}}$ & + \\
\hline $2.0+0.5$ & ST & 50 & $2.0 \pm 0.21^{d}$ & $3.5 \pm 0.40^{f}$ & + \\
\hline & NS & 50 & $2.1 \pm 0.21^{d}$ & $3.5 \pm 0.31^{f}$ & + \\
\hline $2.5+0.1$ & ST & 60 & $2.1 \pm 0.10^{d}$ & $4.1 \pm 0.15^{\mathrm{e}}$ & - \\
\hline & NS & 65 & $2.2 \pm 0.09^{d}$ & $4.2 \pm 0.18^{e}$ & - \\
\hline $2.5+0.2$ & ST & 50 & $1.8 \pm 0.30^{\mathrm{de}}$ & $3.4 \pm 0.50^{f}$ & + \\
\hline & NS & 50 & $1.9 \pm 0.25^{\mathrm{de}}$ & $3.5 \pm 0.41^{f}$ & + \\
\hline $2.5+0.5$ & ST & 20 & $1.2 \pm 0.15^{f}$ & $2.4 \pm 0.25^{g h}$ & + \\
\hline & NS & 20 & $1.3 \pm 0.12^{f}$ & $2.5 \pm 0.31^{g h}$ & + \\
\hline$B A P+I B A$ & & & & & \\
\hline $1.0+0.1$ & ST & 60 & $1.6 \pm 0.30^{\mathrm{de}}$ & $4.4 \pm 0.25^{\text {ed }}$ & + \\
\hline & NS & 65 & $1.7 \pm 0.50^{\mathrm{de}}$ & $4.5 \pm 0.46^{\text {ed }}$ & + \\
\hline $1.0+0.2$ & ST & 40 & $1.3 \pm 0.10^{f}$ & $3.8 \pm 0.30^{\mathrm{ef}}$ & + \\
\hline & NS & 45 & $1.4 \pm 0.19^{f}$ & $4.0 \pm 0.52^{e^{e f}}$ & + \\
\hline $1.0+0.5$ & ST & 25 & $0.8 \pm 0.50^{f g}$ & $2.7 \pm 0.25^{9}$ & ++ \\
\hline & NS & 30 & $0.9 \pm 0.36^{\mathrm{fg}}$ & $2.9 \pm 0.49^{9}$ & ++ \\
\hline $2.0+0.1$ & ST & 75 & $2.4 \pm 0.25^{c d}$ & $5.6 \pm 0.50^{b}$ & + \\
\hline & NS & 80 & $2.5 \pm 0.23^{\mathrm{cd}}$ & $5.8 \pm 0.15^{b}$ & + \\
\hline $2.0+0.2$ & ST & 60 & $2.1 \pm 0.20^{d}$ & $4.7 \pm 0.40^{d}$ & + \\
\hline & NS & 65 & $2.2 \pm 0.21^{d}$ & $4.9 \pm 0.44^{d}$ & + \\
\hline $2.0+0.5$ & ST & 40 & $1.6 \pm 0.15^{\mathrm{de}}$ & $2.8 \pm 0.60^{g}$ & ++ \\
\hline & NS & 45 & $1.8 \pm 0.13^{d}$ & $3.0 \pm 0.25^{9}$ & ++ \\
\hline $2.5+0.1$ & ST & 55 & $1.8 \pm 0.10^{d}$ & $3.6 \pm 0.40^{e f}$ & + \\
\hline & NS & 60 & $1.9 \pm 0.21^{d}$ & $3.7 \pm 0.22^{\mathrm{ef}}$ & + \\
\hline $2.5+0.2$ & ST & 40 & $1.4 \pm 0.50^{\text {ef }}$ & $3.1 \pm 0.25^{9}$ & ++ \\
\hline & NS & 45 & $1.5 \pm 0.20^{\mathrm{ef}}$ & $3.2 \pm 0.11^{g}$ & ++ \\
\hline $2.5+0.5$ & ST & 20 & $1.2 \pm 0.15^{f}$ & $2.0 \pm 0.45^{h}$ & ++ \\
\hline & NS & 25 & $1.3 \pm 0.09^{f}$ & $2.1 \pm 0.32^{\mathrm{h}}$ & ++ \\
\hline BAP + IAA & & & & & \\
\hline $1.0+0.1$ & ST & 55 & $1.4 \pm 0.45^{\mathrm{ef}}$ & $4.1 \pm 0.20^{\mathrm{e}}$ & - \\
\hline & NS & 60 & $1.5 \pm 0.21^{\text {ef }}$ & $4.3 \pm 0.11^{\mathrm{e}}$ & - \\
\hline $1.0+0.2$ & ST & 35 & $1.1 \pm 0.25^{\mathrm{efg}}$ & $3.5 \pm 0.10^{f}$ & + \\
\hline & NS & 40 & $1.2 \pm 0.55^{\mathrm{efg}}$ & $3.6 \pm 0.35^{\mathrm{ef}}$ & + \\
\hline $1.0+0.5$ & ST & 20 & $1.0 \pm 0.10^{\mathrm{fg}}$ & $2.1 \pm 0.15^{\mathrm{h}}$ & ++ \\
\hline & NS & 25 & $1.0 \pm 0.25^{\mathrm{fg}}$ & $2.2 \pm 0.10^{\mathrm{h}}$ & ++ \\
\hline $2.0+0.1$ & ST & 70 & $2.0 \pm 0.30^{d}$ & $5.0 \pm 0.35^{d}$ & + \\
\hline & NS & 75 & $2.1 \pm 0.49^{d}$ & $5.1 \pm 0.55^{d}$ & + \\
\hline $2.0+0.2$ & ST & 60 & $1.8 \pm 0.10^{\mathrm{de}}$ & $4.4 \pm 0.15^{\mathrm{ed}}$ & + \\
\hline & NS & 65 & $1.9 \pm 0.12^{\mathrm{de}}$ & $4.5 \pm 0.41^{\mathrm{ed}}$ & + \\
\hline
\end{tabular}


Table 2: (Continued).

\begin{tabular}{|c|c|c|c|c|c|}
\hline $\begin{array}{l}\text { Different nutrient } \\
\text { media }\end{array}$ & $\begin{array}{l}\text { Types of } \\
\text { explants }\end{array}$ & $\begin{array}{l}\text { Response of } \\
\text { explants (\%) }\end{array}$ & $\begin{array}{l}\text { No. of total shoots per } \\
\text { culture }(\overline{\mathbf{X}} \pm \text { S.E. })\end{array}$ & $\begin{array}{l}\text { Length of the } \\
\text { shoot }(\mathrm{cm})(\bar{X} \pm \text { S.E. })\end{array}$ & $\begin{array}{l}\text { Basal callus } \\
\text { formation }\end{array}$ \\
\hline \multicolumn{6}{|l|}{$B A P+I A A$} \\
\hline \multirow[t]{2}{*}{$2.0+0.5$} & ST & 30 & $1.3 \pm 0.20^{\mathrm{ef}}$ & $2.4 \pm 0.25^{g h}$ & ++ \\
\hline & NS & 35 & $1.4 \pm 0.50^{\mathrm{ef}}$ & $2.5 \pm 0.46^{g h}$ & ++ \\
\hline \multirow[t]{2}{*}{$2.5+0.1$} & ST & 45 & $1.5 \pm 0.10^{\mathrm{e}}$ & $3.2 \pm 0.50^{\mathrm{fg}}$ & + \\
\hline & NS & 50 & $1.6 \pm 0.19^{\mathrm{de}}$ & $3.3 \pm 0.20^{\mathrm{fg}}$ & + \\
\hline \multirow[t]{2}{*}{$2.5+0.2$} & ST & 35 & $1.3 \pm 0.20^{\mathrm{ef}}$ & $2.8 \pm 0.20^{g}$ & ++ \\
\hline & NS & 40 & $1.4 \pm 0.30^{\mathrm{ef}}$ & $2.9 \pm 0.49^{9}$ & ++ \\
\hline \multirow[t]{2}{*}{$2.5+0.5$} & ST & 15 & $1.0 \pm 0.50^{\mathrm{efg}}$ & $1.9 \pm 0.30^{\mathrm{h}}$ & +++ \\
\hline & NS & 20 & $1.1 \pm 0.20^{\mathrm{efg}}$ & $2.0 \pm 0.01^{h}$ & +++ \\
\hline
\end{tabular}

$\mathrm{ST}=$ Shoot Tip; NS = Nodal Segment; $(-)$ represents no response; $(+)$ indicates minor callusing; $(++)$ represents noticeable callusing; $(+++)$ represents abundant callusing

Table 3: BAP and $\mathrm{GA}_{3}$ combined hormonal effect on axillary shoot proliferation from the Shoot tip and Nodal segment explants of in vitro shoots. Same letters in the same column indicate no significant differences between mean $\pm S E$ of treatments at $5 \%$ significance level

\begin{tabular}{|c|c|c|c|c|c|c|}
\hline \multicolumn{2}{|c|}{$\begin{array}{l}\text { Growth } \\
\text { regulators }(\mathrm{mg} / \mathrm{L})\end{array}$} & \multirow[t]{2}{*}{ Types of Explants } & \multirow[t]{2}{*}{$\begin{array}{l}\text { Response of } \\
\text { explants (\%) }\end{array}$} & \multirow[t]{2}{*}{$\begin{array}{l}\text { No. of total shoots per } \\
\text { culture }(\bar{X} \pm \text { S.E. })\end{array}$} & \multirow[t]{2}{*}{$\begin{array}{c}\text { Length of the } \\
\text { shoot }(\mathrm{cm})(\bar{X} \pm \text { S.E. })\end{array}$} & \multirow[t]{2}{*}{$\begin{array}{l}\text { Basal callus } \\
\text { formation }\end{array}$} \\
\hline BAP & $\mathrm{GA}_{3}$ & & & & & \\
\hline \multirow[t]{6}{*}{1.0} & 0.1 & ST & 60 & $1.8 \pm 0.25^{b c}$ & $3.7 \pm 0.10^{f}$ & + \\
\hline & & NS & 65 & $1.9 \pm 0.20^{b c}$ & $3.8 \pm 0.20^{e f}$ & + \\
\hline & 0.2 & ST & 45 & $1.4 \pm 0.20^{d}$ & $4.1 \pm 0.30^{e}$ & + \\
\hline & & NS & 50 & $1.5 \pm 0.51^{\text {cde }}$ & $4.2 \pm 0.21^{\mathrm{e}}$ & + \\
\hline & 0.5 & ST & 25 & $1.2 \pm 0.30^{\mathrm{ed}}$ & $4.9 \pm 0.25^{d}$ & + \\
\hline & & NS & 30 & $1.3 \pm 0.17^{\mathrm{e}}$ & $5.0 \pm 0.20^{d c}$ & + \\
\hline \multirow[t]{6}{*}{2.0} & 0.1 & ST & 75 & $2.7 \pm 0.30^{a}$ & $5.2 \pm 0.10^{c}$ & + \\
\hline & & NS & 80 & $2.8 \pm 0.40^{a}$ & $5.3 \pm 0.10^{c}$ & + \\
\hline & 0.2 & ST & 65 & $2.1 \pm 0.20^{b}$ & $6.0 \pm 0.20^{b}$ & + \\
\hline & & NS & 70 & $2.2 \pm 0.25^{b}$ & $6.1 \pm 0.30^{b}$ & + \\
\hline & 0.5 & ST & 40 & $1.8 \pm 0.10^{c}$ & $7.3 \pm 0.30^{a}$ & - \\
\hline & & NS & 45 & $1.9 \pm 0.29^{b c}$ & $7.5 \pm 0.50^{\mathrm{a}}$ & - \\
\hline \multirow[t]{6}{*}{2.5} & 0.1 & ST & 55 & $2.0 \pm 0.20^{b c}$ & $3.9 \pm 0.10^{\mathrm{e}}$ & + \\
\hline & & NS & 55 & $2.1 \pm 0.09^{b}$ & $4.0 \pm 0.18^{\mathrm{e}}$ & + \\
\hline & 0.2 & ST & 40 & $1.5 \pm 0.30^{\mathrm{cd}}$ & $4.8 \pm 0.15^{d}$ & + \\
\hline & & NS & 40 & $1.6 \pm 0.40^{\mathrm{cd}}$ & $4.9 \pm 0.20^{d}$ & + \\
\hline & 0.5 & ST & 20 & $1.1 \pm 0.15^{\mathrm{e}}$ & $5.3 \pm 0.20^{c}$ & + \\
\hline & & NS & 20 & $1.2 \pm 0.33^{\mathrm{e}}$ & $5.5 \pm 0.30^{c}$ & + \\
\hline
\end{tabular}

ST=Shoot Tip; NS=Nodal Segment; (-) represents no response; (+) indicates minor callusing

of shoots and response rate was low. Total shoot number was found significantly $(\mathrm{P}<0.05)$ higher for the nodal segment of $2.8 \pm 0.40$ on the medium of $2.0 \mathrm{mg} / \mathrm{L} \mathrm{BAP}+0.1 \mathrm{mg} / \mathrm{L} \mathrm{GA}_{3}$. Callus formation was observed slightly in every combination except the high concentrated $\mathrm{GA}_{3}$ with $2.0 \mathrm{mg} / \mathrm{L}$ BAP.

\section{In vitro Root Formation}

For root formation, shoots were cut from cultures grown in vitro and sub-cultured in full and half-strength MS medium supplemented with various concentrations $(0.5,1.0$, and $2.0 \mathrm{mg} / \mathrm{L}$ ) of NAA, IBA, and IAA to find the role of this auxin in roots. Most regenerated shoots produce healthy root systems with basal callus formation. For in vitro rooting, half-strength MS medium is slightly higher than full-strength MS medium. The obtained results are shown in Table 4.

The highest percentage of rooting induction was $75 \%$ recorded in half MS media supplemented with $0.5 \mathrm{mg} / \mathrm{L}$ IBA. The significantly $(\mathrm{P}<0.05)$ highest average root number $(3.1 \pm 0.30)$ was obtained at the same hormonal composition while rooting induction and mean number of roots in full MS media were recorded as $65 \%$ and $2.4 \pm 0.37$, respectively. There was no root formation in $2.0 \mathrm{mg} / \mathrm{L}$ auxins concentration, albeit profuse callusing has emerged at the cut margin. However, IAA concentration showed lower response rate below $50 \%$ in every treatment.

\section{Acclimatization}

In vitro grown rooted plantlets were then collected from the glass vessels and cleared the agar gel from the root of the micro-shoots. The plantlets were then transferred in a small pot containing sun sterilized sand, soil, and humus (1:2:1) and watered regularly, and kept in a growth room for almost 15 days to adapt themselves gradually to the ex vitro environment. Then the potted plantlets were transplanted to the ex vitro environment, where about $95 \%$ of them survived and acclimated successfully on the garden soil after 4 weeks of transplantation (Figure lf). 
Table 4: In vitro root formation on full strength (MS) and half strength (MSS $)$ of MS medium from the in vitro grown micro-shoots. Same letters in the same column indicate no significant differences between mean \pm SE of treatments at $5 \%$ significance level.

\begin{tabular}{|c|c|c|c|c|c|}
\hline Types of auxin & Medium strength & $\begin{array}{l}\text { Response of micro } \\
\text { shoots rooted (\%) }\end{array}$ & $\begin{array}{l}\text { Number of root per micro } \\
\text { shoots }(\overline{\mathrm{X}} \pm \text { S.E. })\end{array}$ & $\begin{array}{l}\text { Average length of the } \\
\operatorname{root}(\mathrm{cm})(\overline{\mathrm{X}} \pm \text { S.E. })\end{array}$ & $\begin{array}{c}\text { Callus formation at } \\
\text { the cutting base }\end{array}$ \\
\hline \multicolumn{6}{|l|}{ IBA } \\
\hline \multirow[t]{2}{*}{0.5} & MS & 65 & $2.4 \pm 0.10^{b}$ & $1.5 \pm 0.20^{b}$ & + \\
\hline & $\mathrm{MSS}_{1}$ & 75 & $3.1 \pm 0.30^{\mathrm{a}}$ & $1.8 \pm 0.30^{\mathrm{a}}$ & + \\
\hline \multirow[t]{2}{*}{1.0} & $\mathrm{MS}^{1}$ & 40 & $1.3 \pm 0.20^{d}$ & $1.0 \pm 0.10^{c}$ & ++ \\
\hline & $\mathrm{MSS}_{1}$ & 50 & $1.5 \pm 0.20^{d}$ & $1.5 \pm 0.10^{b}$ & ++ \\
\hline \multirow[t]{2}{*}{2.0} & MS & - & - & - & +++ \\
\hline & $\mathrm{MSS}_{1}$ & - & - & - & +++ \\
\hline \multicolumn{6}{|l|}{ NAA } \\
\hline \multirow[t]{2}{*}{0.5} & MS & 60 & $2.1 \pm 0.20^{c}$ & $1.1 \pm 0.20^{c}$ & + \\
\hline & $\mathrm{MSS}_{1}$ & 60 & $2.5 \pm 0.20^{b}$ & $1.4 \pm 0.20^{b}$ & + \\
\hline \multirow[t]{2}{*}{1.0} & MS & 30 & $1.2 \pm 0.30^{\mathrm{de}}$ & $0.9 \pm 0.30^{c d}$ & ++ \\
\hline & $\mathrm{MSS}_{1}$ & 35 & $1.3 \pm 0.20^{d}$ & $1.0 \pm 0.30^{c}$ & ++ \\
\hline \multirow[t]{2}{*}{2.0} & $\mathrm{MS}^{-1}$ & - & - & - & +++ \\
\hline & $\mathrm{MSS}_{1}$ & - & - & - & +++ \\
\hline \multicolumn{6}{|l|}{ IAA } \\
\hline \multirow[t]{2}{*}{0.5} & MS & 45 & $1.1 \pm 0.20^{\mathrm{de}}$ & $0.9 \pm 0.20^{\text {cd }}$ & ++ \\
\hline & $\mathrm{MSS}_{1}$ & 50 & $2.1 \pm 0.20^{c}$ & $1.1 \pm 0.30^{c}$ & ++ \\
\hline \multirow[t]{2}{*}{1.0} & $\mathrm{MS}^{1}$ & 25 & $1.0 \pm 0.30^{\mathrm{de}}$ & $0.7 \pm 0.20^{d}$ & ++ \\
\hline & $\mathrm{MSS}_{1}$ & 30 & $1.1 \pm 0.30^{\mathrm{de}}$ & $0.9 \pm 0.20^{\text {cd }}$ & ++ \\
\hline \multirow[t]{2}{*}{2.0} & $\mathrm{MS}^{-1}$ & - & - & - & +++ \\
\hline & $\mathrm{MSS}_{1}$ & - & - & - & +++ \\
\hline
\end{tabular}

$(-)$ represents no response; $(+)$ indicates minor callusing; $(++)$ represents noticeable callusing; $(+++)$ represents abundant callusing.
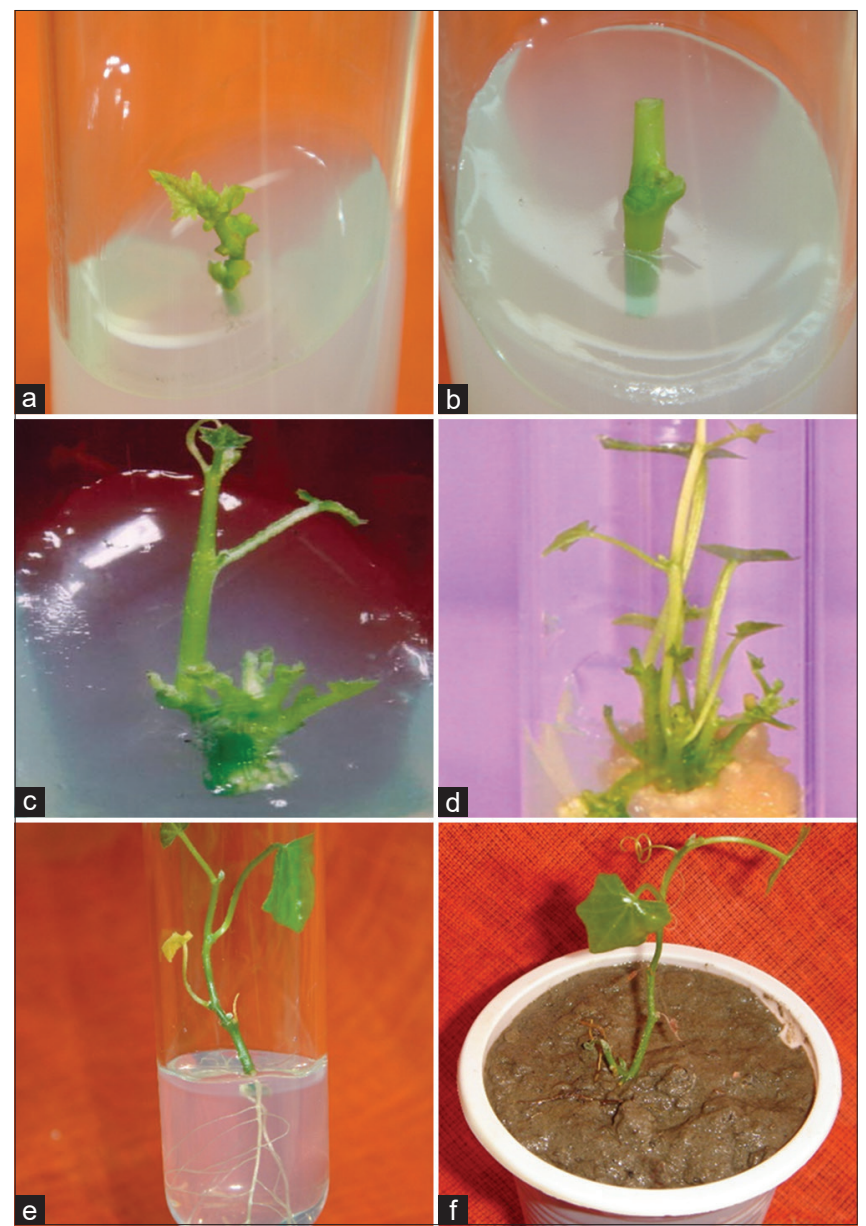

Figure 1: Micropropagation of Cocconia cordifolia (a-b: Shoot tip and node explant, c-d: Axillary shoot proliferation in full-strength MS medium supplemented with $2.0 \mathrm{mg} / \mathrm{L}$ BAP and $0.1 \mathrm{mg} / \mathrm{L}$ NAA from shoot tips (c) and node (d), e: in vitro root formation in half strength MS medium supplemented with $0.5 \mathrm{mg} / \mathrm{L}$ IBA, f: acclimatized plant)

\section{DISCUSSION}

Developing a reproducible protocol for rapid clonal propagation of Cocconia cordifolia, a medicinal plant through micropropagation technique was the main objectives of the current study (Figure 1). Medicinal plants are sources of important therapeutic to relieve human diseases. With the increasing realization of the dangers and health toxicity associated with the indiscriminate use of synthetic and antibiotic medicines, the interest in the use of planted plants and drugs is revived all over the world. Even today, the World Health Organization (WHO) estimates that up to $80 \%$ of people still depend mainly on traditional therapies. It is estimated that about a quarter of prescription drugs contains extracts of plants or active ingredients derived or modeling of plant materials (Tripathi \& Tripathi, 2003).

In vitro clonal propagation has been one of the most using technology for plant preservation and rapid propagation (Anisuzzaman et al., 2008). So, the tissue culture technology is widely exercised for large-scale reproduction and protection of genetic resources of medicinal plants and have been successfully applied to cucurbitaceae plants (Pal et al., 2007; Khalekuzzaman et al., 2012; Alam et al., 2019).

In aseptic condition field derived samples are necessary to be surface sterilized for the primary establishment of the culture. Fungus and bacteria are the most common contaminator observed in in vitro culture. The nutrient medium used in tissue culture techniques is most suitable for growth that inhibits the regeneration and development of the desired experimental plants. Therefore, $\mathrm{HgCl}_{2}$ used as one of the effective surface sterilants and is considered as a potent surface sterilization agent though its residual inhibitory effect is also greater than the other sterilization agents generally is used in tissue culture technique 
(Bhojwani and Razdan, 1986). So $0.1 \% \mathrm{HgCl}_{2}$ treatment for 6 minutes was found the most workable condition for surface sterilization for bud propagation as a maximum of $90 \%$ in the case of nodal segments and $85 \%$ of shoot tips were found contamination-free cultures without considerable tissue death. Generally a two-step process, $0.525 \%$ sodium hypochlorite solution treatment for 10-20 min, and then immerse them in $70 \%$ ethanol, was used by many autohrs (Dagnino et al., 1991; Verma et al., 2004;). Even Verma et al. (2004) used a layer of Rifampicin $(100 \mathrm{mg} / \mathrm{ml})$ solution on medium surface in addition to this, to prevent bacterial contamination and described the harmful effects of sodium hypochlorite on shoot apices. The finding of this investigation of using $0.1 \% \mathrm{HgCl}_{2}$ treatment was similar with the concluded results of Alam et al., (2004); Anisuzzaman et al., (2008) and Alam et al., (2013) but there are slight differences in duration of differential sensitivity of $\mathrm{HgCl}_{2}$ to different plant species.

Three different strengths of MS medium (MS, MMS and $\mathrm{MMS}_{2}$ ) were used in the present investigation. Among these, full-strength MS medium produced significantly the best results irrespective of growth regulator supplements (Table 1). However, most plants exhibited varying degrees of response better than the woody ones (Bhojwani \& Razdan, 1986). This medium percentage of explants shoot proliferation ranged from $40-85 \%$ for shoot tips and 45-95\% for nodal explants. Number of shoots per explants ranged from $1.5 \pm 0.35-4.5 \pm 0.46$ for shoot tips and $1.7 \pm 0.16-5.0 \pm 0.55$ for nodal explants, which indicates full ionic concentration is helpful for optimum shoot production (Table 1). Venkateshwarulu et al. (2001) also reported similar findings in Coccinia indica, and Tefera and Wannakrairoj (2004) in Aframomum corrorima.

Between two types of explants obtained from mature plants, nodal segments showed comparatively better results than shoot-tip explants for axillary shoot proliferation (Figure la-d). For high-frequency axillary shoot regeneration, nodal explants of in vitro grown plantlet are the best explant. In the present investigation, in vitro developed nodal explants produced a significantly higher number of shoots in $100 \%$ culture (Table 2). Similar findings were also noted in Zehneria scabra (Anand \& Jeyachandran, 2004), Hyptis suaveolens (Britto et al., 2001). The effects of cytokines on shoot proliferation from nodal segment and shoot tip were tested on using different concentrations of BAP and Kin (Table 2). Among these media combinations, BAP $(2.0 \mathrm{mg} / \mathrm{L})$ showed better proliferation rate than Kin. The superiority of BAP in producing in vitro axillary shoots has also been established in other medicinal plants like - Hyptis suaveolens (Britto et al., 2001), Zehneria scabra (Anand \& Jeyachandran, 2004). The combination of BAP and NAA was found effective in Cocconia indica on MS medium fortified with $1.5 \mathrm{mg} / \mathrm{L} \mathrm{BAP}$ and $0.5 \mathrm{mg} / \mathrm{L} \mathrm{NAA}$ (Sarker et al., 2009).

Therefore, the effect of different concentrations and combinations of BAP with three auxins (NAA, IBA, and IAA) on shoot multiplication from nodal segments and shoot tip explants were evaluated (Table 2). Among these media combinations, $\mathrm{BAP}+\mathrm{NAA}$ showed a significantly $(\mathrm{P}<0.05)$ better proliferation rate than $\mathrm{BAP}+\mathrm{IBA}$ and $\mathrm{BAP}+\mathrm{IAA}$ combinations. In shoot proliferation medium, a comparatively higher concentration of BAP with a lower concentration of NAA showed the best results, and the significantly $(\mathrm{P}<0.05)$ maximum number of $3.0 \pm 0.41$ shoots per explants was observed on a medium having $2.0 \mathrm{mg} / \mathrm{L}$ BAP with $0.1 \mathrm{mg} / \mathrm{L} \mathrm{NAA}$. The highest mean number of shoots per explant was produced in media having $2.0 \mathrm{mg} / \mathrm{L}$ $\mathrm{BAP}+0.1 \mathrm{mg} / \mathrm{L} \mathrm{NAA}$.

Moreover, BAP in combine with NAA showed better performance than the other combinations for the bud multiplication in shoot tip and nodal explants as Kashem and Rahman (2018) found $100 \%$ regeneration rate in Cocconia grandis whereas Patel and Ishnava (2015) reported the length of shoot was $5.9 \pm 1.0 \mathrm{~cm}$ in the same hormonal combination.

Then for further analysis, $\mathrm{GA}_{3}$ were used in different concentration to combine with BAP to improve the shoot length as reported in a wide range of species (Alam et al., 2004). However, the total shoots number and response rate were found lower than sole supplement of BAP and NAA combination treatment.

So, $2.0 \mathrm{mg} / \mathrm{L} \mathrm{BAP}$ alone as PGR source and $2.0 \mathrm{mg} / \mathrm{L} \mathrm{BAP} \mathrm{+}$ $0.1 \mathrm{mg} / \mathrm{L}$ NAA combine supplement proved to be the best PGR for C. cordifolia in this current study as shoot tips and nodal segments were significantly $(\mathrm{P}<0.05)$ much higher shoots number with higher length than other hormonal treatment and the result is in support with the findings of Karim and Ahmed (2010) in teasle gourd.

The regenerated micro-shoots were separated from the cultures for the development of roots at their cut bases (Figure le). Rooting of regenerated shoots is particularly important for the establishment of tissue culture-derived shoots. Pierik (1987) stated that the most effective auxins were definitely IBA and NAA for rooting. Herbaceous plants require fewer auxin concentrations than the woody plants. There have been several published reports on the roots induction by auxin in in vitro developed shoots of some important medicinal plants (Begum et al., 2003). To induce adventitious roots, $3-4 \mathrm{~cm}$ long shoot cut from in vitro proliferated shoots which were cultured on full and half strength of MS medium with growth stimulators of $0.5,1.0$, and $2.0 \mathrm{mg} / \mathrm{L}$ either of IBA, NAA or IAA (Table 4). Among three types of auxin treatment on root formation, the half strength MS medium supplemented with $0.5 \mathrm{mg} / \mathrm{L}$ IBA is found the most satisfactory. The highest percentage $(75 \%)$ of root growth was obtained in $1 / 2 \mathrm{MS}$ with $0.5 \mathrm{mg} / \mathrm{L}$ IBA. The use of half nutritious MS medium for rooting to in vitro shoots has been a prevalent practice that is also reported by Sarker et al. (2009) where the authors observed best root initiation response in $1.5 \mathrm{mg} / \mathrm{L} \mathrm{IBA}$ incorporated with $0.5 \mathrm{mg} / \mathrm{L}$. Sundari et al. (2011) also reported IBA as profound auxin for root formation as $100 \%$ formed root in $0.1 \mathrm{mg} / \mathrm{L}$ IBA contained MS medium. The next suitable auxin was NAA, but it produced callus at the cut base of the root.

In vitro regenerated plantlets of Coccinia cordifolia were transferred to the soil under ex vitro conditions. Of the transplanted plantlets, about $95 \%$ of them could tolerate 
transplantation shock and survived under ex vitro environment (Figure lf). The rest of the transplants could not survive due to either desiccation or microbial overgrowth. Damping-off and necrosis of the transplants were also observed during acclimatization in ex vitro conditions in the case of Solanum nigrum (Ara et al., 1993). Since in vitro regenerated seedlings are very fragile, special arrangements are required, such as controlled greenhouse conditions, the use of soilless potting mixtures (such as perlite, vermiculite, peat plugs), and the use of fungicides, so that the seedlings can easily and successfully adapt to the environment.

\section{CONCLUSION}

The findings of the study for in vitro establishment of C. cordifolia have been standardized with shoots regeneration, multiplication, rooting formation, and acclimatization. With full-strength MS medium supplemented with $2.0 \mathrm{mg} / \mathrm{L}$ BAP were found productive as regeneration rate and shoot number and length was maximum at $5 \%$ significance level. Nodal segments was found as paramount for in vitro shoot multiplication. Further, the plant had a 95\% survival rate at ex vitro condition after getting maximum roots at $0.5 \mathrm{mg} / \mathrm{L}$ IBA in half-strength MS medium. Information obtained from different steps of the study would be of use for initiation of any experiment on tissue culture and in vitro manipulation of Coccinia cordifolia for the best use of the plant parts in the pharmaceutical industry.

\section{ACKNOWLEDGMENT}

Authors acknowledge the Chairman and the teachers of Department of Botany for their continuous suggestions and feedbacks.

\section{REFERENCES}

Alam, I., Sharmin, S. A., Naher, M. K., Alam, M. J., Anisuzzaman, M., \& Alam, M. F. (2013). Elimination and detection of viruses in meristemderived plantlets of sweetpotato as a low-cost option toward commercialization. 3 Biotech, 3(2), 153-164. https://doi.org/10.1007/ s13205-012-0080-6

Alam, J., Alam, I., Sharmin, S. A., Rahman, M., Anisuzzaman, M., \& Alam, M. F. (2010). Micropropagation and antimicrobial activity of Operculina turpethum (Syn. '/pomoea turpethum'), an endangered medicinal Plant. Plant Omics, 3(2), 40-46.

Alam, M. F., Banu, M. L. A., Swaraz, A. M., Parvez, S., Hossain, M., Khalekuzzaman, M., \& Ahsan, N. (2004). Production of virus free seeds using meristem culture in tomato plant under tropical conditions. Journal of Plant Biotechnology, 6(4), 221-227.

Alam, M. F., Mondol, P. C., Roy, S. K., Anisuzzaman, M., Parvez, M. S., Ray, S. K., Mahzabin, F., Tanny, T., \& Alam, I. (2019). Determination of Apposite plant regeneration protocol for several cucurbits through direct and indirect organogenesis. Horticulture Biotechnology Research, 5, 4-13. https://doi.org/10.25081/hbr.2019.v5.5279

Amin, M. N., Azad, M. A. K., \& Begum, F. (1997). In vitro plant regeneration from leaf-derived callus cultures of Adhatoda vasica Nees. Plant Tissue Culture, 7(2), 109-115.

Anand, S. P., \& Jeyachandran, R. (2004). In vitro multiple shoot regeneration from nodal explants of Zehneria scabra (Lf) Sonder - An important medicinal climber. Plant Tissue Culture, 14(2), 101-106.

Anand, S. P., Jeyachandran, R., \& Xavier, T. F. (2003). Antibacterial activities of Zehneria scabra root extracts. Journal of Tropical Medicinal Plants, 4(2), 173-180.
Anisuzzaman, M., Sharmin, S. A., Mondal, S. C., Sultana, R., Khalekuzzaman, M., Alam, I., \& Alam, M. F. (2008). In vitro microrhizome induction in Curcuma zedoaria (Christm.) Roscoe - A conservation prioritized medicinal Plant. Journal of Biologica/ Sciences, 8(7), 1216 1220. https://doi.org/10.3923/jbs.2008.1216.1220

Ara, M., Jahan, A., \& Hadiuzzaman, S. (1993, December 19-21). In vitro plant regeneration from leaf explant of Solanum sisymbrifolium Lamk in Bangladesh. International Plant Tissue Culture Conference, Dhaka.

Barna, K. S., \& Wakhlu, A. K. (1988). Axillary shoot induction and plant regeneration in Plantago ovata Forssk. Plant Cell, Tissue and Organ Culture, 15(2), 169-173. https://doi.org/10.1007/BF00035758

Begum, F., Amin, M. N., Islam, S., Azad, M. A. K., \& Rehman, M. M. (2003). In Vitro Plant Regeneration from Cotyledon-Derived Callus of Three Varieties Pummelo (Citrus Grandis (L.) Osb.). Journal of Biological Science, 3(8), 751-759.

Bhattacharya, B., Lalee, A., Mal, D. K., \& Samanta, A. (2011). In-vivo and in-vitro anticancer activity of Coccinia grandis (L.) Voigt. (Family: Cucurbitaceae) on Swiss albino mice. Journal of Pharmacy Research, 4(3), 567-569.

Bhattacharya, B., Samanta, M., Pal, P., Chakraborty, S., \& Samanta, A. (2010). In vitro evaluation of antifungal and antibacterial activities of the plant Coccinia grandis (L.) voigt (Family-Cucurbitaceae). Journal of Phytology, 2(11), 52-57.

Bhojwani, S. S., \& Razdan, M. K. (1986). Plant Tissue Culture: Theory and Practice (Developments in Crop Science). Amsterdam: Elsevier.

Borah, A. R., Anbumalarmathi, J., \& Sharmili, S. A. (2019). In vitro propagation of Coccinia indica (L.) Voigt. from internodal segments. Indian Journal of Agricultural Research, 53(2), 202-207.

Britto, J. O. H. N., Robinson, S. J. J., Natarajan, E., \& Arockiasamy, D. I. (2001). Micropropagation of Hyptis suaveolens [L.] Poit.[Labiatae] Through Nodal Culture. Advances in Plant Sciences, 14(2), 561-566.

Datta, K., \& Datta, S. K. (1984). Auxin induced clonal multiplication of Holarrhena antidysenterica by tissue culture. Journal of Tree Sciences, 3(1-2), 45-52.

Deshpande, S. V., Patil, M. J., Daswadkar, S. C., Suralkar, U., \& Agarwal, A. (2011). A study on anti-inflammatory activity of the leaf and stem extracts of Coccinia grandis L. voigt. International Journal of Applied Biology and Pharmaceutical Technology, 2(3), 247-250.

Devendra, N. K., Rajanna, L., Sheetal, C., \& Seetharam, Y. N. (2009). In vitro Clonal Propagtion of Trichosanthes cucumerina L. var. cucumerina. Plant Tissue Culture and Biotechnology, 18(2), 103-111. https://doi.org/10.3329/ptcb.v18i2.3270

Girish, C., Balakrishnan, S., Koner, B. C., Jayanthi, S., Rao, K. R., Rajesh, B., \& Pradhan, S. C. (2011). Evaluation of antiulcer activity of Coccinia grandis leaves. Research Journal of Pharmacology and Pharmacodynamics, 3(2), 92-95.

Hussain, A., Wahab, S., Rizvi, A., \& Hussain, M. (2011). Macroscopical, anatomical and physio-chemical studies on leaves of Coccinia indica Wight $\&$ Arn., growing wildly in eastern Uttar Pradesh region of India. Indian Journal of Natural Products and Resources, 2(1), 74-80.

Jamwal, A., \& Kumar, S. (2019). Antidiabetic activity of isolated compound from Coccinia indica. Indian Journal of Pharmaceutical Education and Research, 53(1), 151-159.

Karim, M. A., \& Ahmed, S. U. (2010). Somatic embryogenesis and micropropagation in teasle gourd. International Journal of Environmental Science and Development, 1(1), 10-14.

Kashem, M. A., \& Rahman, M. M. (2018). Micropropagation of Coccinia grandis (Linn.) Voigt. Through organogenesis. European Journal of Biotechnology and Bioscience, 6(6), 63-68.

Khalekuzzaman, M., Khatun, M., Rashid, M. H., Sheikh, M. I., Sharmin, S. A. \& Alam, I. (2012). Micropropagation of an elite F1 watermelon (Citrullus lanatus) hybrid from the shoot tip of field grown plants. Brazilian Archives of Biology and Technology, 55(3), 335-340. https://doi. org/10.1590/S1516-89132012000300002

Kuriyan, R., Rajendran, R., Bantwal, G., \& Kurpad, A. V. (2008). Effect of supplementation of Coccinia cordifolia extract on newly detected diabetic patients. Diabetes care, 31(2), 216-220. https://doi. org/10.2337/dc07-1591

Murashige, T. \& Skoog, F. (1962). A revised medium for rapid growth and bioassays with tobacco tissue cultures. Physiologia Plantarum, 15, 473-497. https://doi.org/10.1111/j.1399-3054.1962.tb08052.x

Nachimuthu, S. Suresh, K., Sadhasivam B., Veerichetty V., \& Ponnusamy R. (2018). Development and evaluation of antiinflammatory ointment using aqueous extract of Coccinia grandis L. International Journal of 
Green Pharmacy, 12(3), S589-S596.

Nataraja, K., \& Ganapathi, T. R. (1989). In vitro plantlet regeneration from cotyledons of Helianthus annuus cv. Morden (sunflower). Indian Journal of Experimental Biology, 27(9), 777-779.

Pal, S. P., Alam, I., Anisuzzaman, M., Sarker, K. K., Sharmin, S. A., \& ALAM, M. F. (2007). Indirect organogenesis in summer squash (Cucurbita pepo L.). Turkish Journal of Agriculture and Forestry, 31(1), 63-70.

Patel, A. R., \& Ishnava, K. B. (2015). In vitro shoot multiplication from nodal explants of Coccinia grandis (L.) Voigt. and it's antidiabetic and antioxidant activity. Asian Journal of Biologica/ Sciences, 8(2), 57-71. https://doi.org/10.13140/RG.2.1.2917.9603

Pekamwar, S. S., Kalyankar, T. M., \& Kokate, S. S. (2013). Pharmacological activities of Coccinia grandis. Journal of Applied Pharmaceutical Science, 3(5), 114-119. https://doi.org/10.7324/JAPS.2013.3522

Pierik, R. L. M. (1997). In vitro culture of higher plants. Dordrecht: Springer science \& business media. https://doi.org/10.1007/978-94-011-5750-6

Ravikumar, S., Inbaneson, S. J., \& Suganthi, P. (2012). In vitro antiplasmodial activity of ethanolic extracts of South Indian medicinal plants against Plasmodium falciparum. Asian Pacific Journal of Tropical Disease, 2(3), 180-183. https://doi.org/10.1007/s00436-010-2128-z

Roy, G. K., \& Khan, S. A. (2020). Preliminary taxonomic study on homestead flora of four districts of Bangladesh: Magnoliopsida. Bangladesh Journal of Plant Taxonomy, 27(1), 37-65. https://doi.org/10.3329/bjpt.v27i1.47567

Sarker, P. F. M. S., Jahan, R., \& Rahmatullah, M. (2009). In vitro regeneration of Coccinia grandis (L.) Voigt., an indigenous medicinal plant of Bangladesh. African Journal of Traditional, Complementary and Alternative Medicines, 351-352.

Shakya, V. K. (2008). Antidiabetic activity of Coccinia indica in streptozotocin induced diabetic rats. Asian Journal of chemistry, 20(8), 6479-6482.

Sharmin, S. A., Alam, M. J., Sheikh, M. M. I., Zaman, R., Khalekuzzaman, M., Mondal, S. C., Haque, M. A., Alam, M. F., \& Alam, I. (2013). Micropropagation and antimicrobial activity of Curcuma aromatica Salisb., a threatened aromatic medicinal plant. Turkish Journal of
Biology, 37(6), 698-708. https://doi.org/10.3906/biy-1212-11

Sivaraj, A., Jenifa, B. P., Kavitha, M., Inbasekar, P., Senthilkumar, B., \& Panneerselvam, A. (2011). Antibacterial activity of Coccinia grandis leaf extract on selective bacterial strains. Journal of Applied Pharmaceutical Science, 1(7), 120-123

Sundari, U. T., Sherif, N. A., Benjamin, J. F., \& Rao, M. V. (2011). Rapid micropropagation via axillary bud proliferation of Coccinia grandis (L.) Voigt. from nodal segments. Plant Tissue Culture and Biotechnology, 21(1), 75-82.

Tamilselvan, N., Thirumalai, T., Elumalai, E. K., Balaji, R., \& David, E. (2011) Pharmacognosy of Coccinia grandis: a review. Asian Pacific Journal of Tropical Biomedicine, 1(2), S299-S302. https://doi.org/10.1016/ S2221-1691(11)60176-7

Taur, D. J., \& Patil, R. Y. (2011). Mast cell stabilizing, antianaphylactic and antihistaminic activity of Coccinia grandis fruits in asthma. Chinese Journal of Natural Medicines, 9(5), 359-362. https://doi.org/10.3724/ SP.J.1009.2011.00359

Tefera, W., \& Wannakrairoj, S. (2004). A micropropagation method for korarima (Aframomum corrorima (Braun) Jansen). Science Asia, 30, 1-7.

Tripathi, L., \& Tripathi, J. N. (2003). Role of biotechnology in medicinal plants. Tropical Journal of Pharmaceutical Research, 2(2), 243-253.

Verma, V. M., Aikne, J., \& David, J. (2004, September). Micropropagation and germplasm conservation of sweet potato (/pomoea batatas (L.) Lam.) by tissue culture. Proceedings of the $4^{\text {th }}$ International Crop Science Congress, Brisbane, Australia.

Yadav, G., Mishra, A., \& Tiwari, A. (2010). Medical properties of ivy gourd (Cephalandra indica): A review. International Journal of Pharmaceutical Research and Development, 2(9), 92-98.

Zakaria, D. M., Islam, M., Anisuzzaman, S. M., Kundu, S. K., Khan, M. S., \& Begum, A. A. (2011). Ethnomedicinal survey of medicinal plants used by folk medical practitioners in four different villages of Gazipur district, Bangladesh. Advance in Natural and Applied Sciences, 5(4), 392-399. 